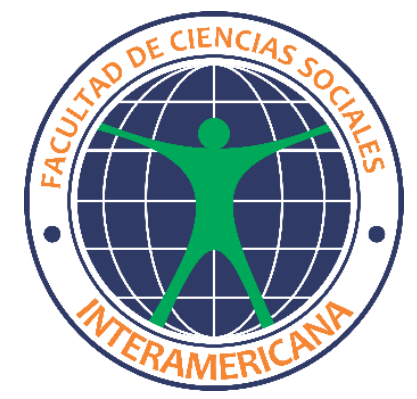

FACULTAD INTERAMERICANA DE CIENCIAS SOCIALES MESTRADO EM CIÊNCIAS DA EDUCAÇÃO

FABRÍCIO ZOUAIN MIRANDA

A INFLUÊNCIA DAS NOVAS TECNOLOGIAS NA EDUCAÇÃO 
FABRICIO ZOUAIN MIRANDA

\section{A INFLUÊNCIA DAS NOVAS TECNOLOGIAS NA EDUCAÇÃO}

Artigo apresentado como requisito parcial para obtenção do título de Mestre em Ciências da Educação da Facultad Interamericana de Ciencias Sociales.

Orientador (a): Prof. (a) Dra. Kelly F. S. Ricardo 


\title{
A INFLUÊNCIA DAS NOVAS TECNOLOGIAS NA EDUCAÇÃO
}

\author{
Fabricio Zouain Miranda ${ }^{1}$
}

Resumo: A incorporação da tecnologia na educação é um sinal crescente da necessidade que surge na sociedade de hoje do uso deste modelo nos processos educativos. Assim, para compreender a importância do papel que desempenham o uso das tecnologias na educação é necessário avaliar os diversos fatores envolvidos, na formação e consolidação de um desenvolvimento sustentável em sintonia com os tempos, com base em educação de qualidade. Portanto, este artigo tem como objetivo demonstrar a importância das tecnologias como ferramentas que ajudam no desenvolvimento do ensino-aprendizagem que é implementado, facilitando a aquisição do conhecimento mais imediato, abrangente, preciso e adaptado às novas realidades e permitindo que os professores implementem de forma mais eficaz o seu trabalho educacional. Salienta, igualmente, o papel fundamental desempenhado pelos professores na busca do conhecimento e uso dessas tecnologias, em razão da importância didática que eles têm e de acordo com o bom uso a ser dado.

Palavras chave: Desenvolvimento. Aprendizagem. Professores. Ensino.

\section{INTRODUÇÃO}

O impacto da tecnologia da informação, a globalização e o rápido crescimento das economias têm gerado preocupação com a eficiência econômica no contexto da política de educação, que enfatiza o desenvolvimento das múltiplas inteligências dos estudantes em sala de aula. Como resultado, os estudantes aprendem a utilizar o conhecimento de maneira distinta e com uma variedade de meios para resolver problemas simples e complexos, desenvolvendo assim o aprendizado.

O uso da tecnologia na educação, de acordo com especialistas, é um fenômeno de grande significado social, pois, são um meio utilizado na promoção da educação a partir do qual pode fortalecer o processo de leitura e escrita, considerando que os estudantes de hoje estão mais sensíveis a um ambiente digital, pois, permite um maior grau de interação e conexão com dispositivos eletrônicos, telefones celulares, televisão digital, videogames e do uso regular da internet.

\footnotetext{
${ }^{1}$ Graduado em Tecnologia de Processamento de Dados pela Faculdade Capixaba de Informática - FACIN, PósGraduado em Administração Contábil e Financeira e em Gestão Empresarial pelo Centro de Pesquisa e PósGraduação da FAESA - Faculdades Integradas Espírito-Santenses, atua como Instrutor Estratégico da Universidade Corporativa CAIXA - Caixa Econômica Federal.E-mail: fabricio.zouain@gmail.com
} 
Neste sentido, novas possibilidades se abrem, a partir de diferentes exigências, levando a um potencial que pode ser realizado ou não, em maior ou menor grau, dependendo do contexto e de como será implementado. As tecnologias podem facilitar ou dificultar o uso pretendido, especificamente nos casos em que os alunos apresentam uma deficiência digital, tornando-se um fator de desigualdade. Isso leva a reflexão sobre como as tecnologias devem ser exploradas na educação, de modo que contribuam para o desenvolvimento da aprendizagem.

Em contraste com a educação tradicional, o ensino e as opções educacionais com apoio das tecnologias que têm o maior impacto, tornando-se mais eficiente do que tradicionalmente tem sido. No entanto, a utilização das tecnologias nas escolas ainda é limitada por fatores externos, como o acesso aos recursos, incentivos para mudança, adequação do conhecimento, motivação, políticas para educação, entre outros. Indicando que a penetração da tecnologia nas escolas é mais difícil do que parece e se espera.

\section{FUNDAMENTAÇÃO TEÓRICA}

\subsection{Como a tecnologia está transformando a educação}

Antes da revolução digital, ensino foi baseado no uso de caneta, papel e dezenas de livros cheios de informações e conteúdo estático. Elementos que definem uma forma muito clara para os alunos.

Ao longo do século, com a expansão da revolução digital a todas as áreas da vida diária, a educação vem passando por uma transformação gradual. Um processo em que papel e lápis são deixados de lado, mudando para a tela de toque, e caneta para teclado. Assim, a metodologia tradicional estática abre caminho para o dinamismo, a criatividade e modularidade da tecnologia.

Neste cenário, foi analisado a forte influência da revolução tecnológica nas escolas em que as necessidades e os conhecimentos dos alunos são atendidas e assimiladas de maneira dinâmica, onde as cabeças do futuro estão sendo moldadas sob uma concepção totalmente diferente, aprimorando ainda mais as funções cognitivas.

Segundo Moser (2011), várias transformações ocorreram na educação de acordo com o período e o contexto social, político, cultural e religioso. Observando que a tecnologia nos apresenta diversas formas de interagir com a sociedade no dia a dia, Kloch e Junior (2010) afirmam de que forma o homem tem sua vida influenciada pelas novas tecnologias: 
[...] Em casa a informática está presente não só no computador, mas também no forno de micro-ondas, na televisão, no controle de segurança, no portão eletrônico, na geladeira e em muitos outros itens que precisam de controle e processamentos de informações. No lazer podemos encontrar a informática nos jogos eletrônicos, parque de diversões, na internet, no celular e em tantas outras formas de utilização. No trabalho encontramos a informática nas diversas formas de comunicação, no suporte às nossas atividades, no apoio aos serviços de produção e principalmente no controle de todas as atividades envolvidas. (Kloch e Junior, 2010, p.3).

Ao longo da história, sempre ocorreram evoluções e mudanças, entretanto, nas últimas duas décadas, essas aconteceram de forma mais acelerada e com um impacto maior na sociedade.

\subsection{O sistema de ensino tradicional e sua transformação}

Educação e transferência de conhecimento têm sido uma das premissas básicas da sociedade por mais de dois mil anos. Com base nas necessidades da época, egípcios, gregos e romanos já tinham sistemas de transferência de conhecimento, modelos estes, semelhantes aos utilizados na educação ainda hoje. Desde aquela época as transferências de conhecimento ocorriam de duas formas distintas, aulas teóricas e aulas práticas.

As práticas foram os mais comuns: os mestres artesãos ensinaram os trabalhos e ofícios para os seus descendentes e aprendizes, que acabaria por melhorar as técnicas gradualmente ao longo do tempo. Já as Teóricas, eram menos comuns, mas o mais próximo ao modelo atual, grandes personalidades como Sócrates, Pitágoras e Platão dedicaram muito do seu tempo à investigação e reflexão para ensinar e repassar seus conhecimentos a grupos selecionados de pessoas, garantindo que seu legado permanecerá imóvel com o progresso histórico da sociedade humana.

Séculos mais tarde, os métodos de ensino já tinham avançado para um nível superior. As primeiras universidades foram fundadas em países como Marrocos, Inglaterra, Itália e Espanha, epicentros dos movimentos sociais e culturais da época. Davam grande ênfase em temas como arte, ciência ou história, áreas-chave para o progresso naquele momento. Gradualmente, o sistema de ensino começou a tomar forma.

Conforme Tafner e Silva (2012), no século XV, a tecnologia da comunicação já se fazia presente na vida das pessoas. Com a invenção da imprensa por Gutemberg houve significativas mudanças sociais como a reforma e a divulgação das novas ideias na Europa e no mundo.

[...] a imprensa permitiu maior acesso à informação, facilitou o processo de divulgação de ideias, democratizou o conhecimento, potencializou reformas e 
revoluções. Na educação não poderia ser diferente, pois a partir desse momento os livros passaram a serem impressos. [...]. (Tafner e Silva 2012, p.3)

No entanto, a educação como a conhecemos hoje não começou a ser formada até o século XIX. Os vários movimentos éticos e sociais que ocorreram durante os séculos anteriores levaram o homem a abrir a porta do conhecimento para o progresso, a chegada da classe burguesa e seus ideais progressistas desempenhou um papel fundamental. Na Europa, reis, rainhas e nobres, promoveram por meio de leis a redução e até o desaparecimento do analfabetismo entre a população.

Ao longo dos anos, as leis continuam provocando reformas educacionais e ajustes de acordo com a evolução dos tempos. Algumas destas, também trouxeram mudança na metodologia que nos leva à situação atual.

O sistema de ensino atual é o resultado de séculos de transição progressiva e exponencial.

Antes de entrar em detalhes e aprender como a tecnologia está mudando e como as escolas irão alterar o futuro, é preciso entender e analisar a metodologia utilizada pelo professor hoje. Isto, pode ser resumido em dois pontos principais:

- Ensino - As habilidades são ensinadas em sala de aula através da transmissão oral do conhecimento, o uso de livros didáticos e aulas expositivas são explicadas com mais detalhes, além de uma série de exercícios e trabalhos que são utilizados para tentar reforçar o aprendizado aos estudantes.

- Avaliação - Na maioria dos casos, a aquisição de conhecimento é verificada através de exames periódicos em que o aluno enfrenta questões teóricas e práticas associados com o assunto. Depois disso, uma pontuação (geralmente entre 0 e 10), reflete o nível de conhecimento que o aluno demonstrou sobre o assunto.

Esta metodologia clássica, embora tenha sido eficaz em muitos casos, reflete inúmeras deficiências que levam os estudantes a desmotivação, altruísmo e, acima de tudo, a uma aquisição de conhecimento muito superficial.

Inicialmente, a inclusão e integração da tecnologia ocorre de maneira muito superficial. A grande maioria dos professores e, claro, os alunos assumem que a integração da tecnologia nas escolas é apenas para substituir itens como lápis ou papel para ferramentas mais avançadas, como tablets, notebooks e plataformas virtuais.

Mas isso é apenas o topo do iceberg. A chegada dessas novas ferramentas para as escolas deve ser imperativamente acompanhada por uma mudança no nível metodológico. O mundo em que vivemos e, sobretudo, o futuro iminente que nos espera, coloca inteiramente diferentes 
desafios que enfrentamos no passado. O modelo de ensino está em plena metamorfose, e a educação deve acompanhá-lo.

Em um mundo cada vez mais conectado, o desenvolvimento de habilidades como memória começa a perder valor. Os professores devem incentivar outras habilidades, como flexibilidade, trabalho em equipe, conhecimento e criatividade. Todos eles têm um valor maior no futuro que se aproxima.

Um exemplo desta metamorfose necessária pode ser observado em temas como história. A metodologia tradicional é baseada na memorização maciça de conceitos, eventos e datas, semanas mais tarde, devem ser expostos em uma avaliação ou exame escrito ou oral. Dias depois, o trabalho realizado pelo aluno obtém uma qualificação específica que certifica a aquisição correta do conhecimento associado com o assunto.

O problema com esta metodologia é que a compreensão e resolução de tal conhecimento é somente um pano de fundo. O objetivo do estudante é passar no teste estabelecido pelo professor, na maioria dos casos, as metodologias contribuem para esse objetivo comum. Não importa que os estudantes esqueçam dias depois o que foi estudado, nem tão pouco, que o estudante não tire valor desses ensinamentos, datas, nomes e eventos concretos. Tudo o que importa é que o aluno atinja a classificação desejada, o que se traduz em um vazio e de pouca utilidade do conhecimento.

Este complexo problema é ainda agravado se você olhar para a facilidade com a qual podemos ver as informações na internet. Atualmente, basta ter um relógio inteligente ou um smartphone perto para se consultar qualquer coisa em segundos. No futuro, será ainda mais radical: o nosso próprio corpo vivo conectado à internet, e todas as informações existentes na rede estarão à nossa disposição em questão de milissegundos.

Memorizar então, torna-se sem sentido. O importante é compreender, analisar e estabelecer o conhecimento de uma forma mais profunda e mais criativa, de forma que realmente enriqueça o estudante e contribua para o seu futuro profissional e social.

A chegada dos primeiros produtos de tecnologia de dados nas escolas data da segunda metade do século XX. As principais universidades norte-americanas começaram a oferecer em suas salas de aula de maneira muito esporádica, breves momentos de contato dos seus alunos com computadores como o Apple I, a mais comum entre elas foi o Massachusetts Institute of Technology - MIT.

No entanto, no Brasil, somente a partir dos anos dois mil, que a tecnologia começou a tomar um papel maior de destaque nas instituições de ensino. A utilização dos computadores, 
a chegada de novos formatos multimídia e expansão da internet como um método universal de comunicação abriram as portas para as tecnologias nas escolas.

\subsection{Soluções tecnológicas utilizadas na educação}

Hoje, empresas de tecnologia e instituições acadêmicas continuam a conduzir esta corrida tecnológica nas salas de aula. A gigante Microsoft (https://www.microsoft.com/ptbr/education), por exemplo, concentra grande parte de seus esforços no desenvolvimento de software e serviços que atendam às necessidades específicas de sala de aula de ensino, a empresa coloca grande ênfase na integração de serviços como o Office, Onedrive ou Skype, que permitem que os alunos e professores transmitam e recebam o conteúdo de uma forma mais versátil e em consonância com os tempos.

Segundo Levy (1999) a sociedade contemporânea vive conectada à mídia, o que acarreta uma mudança considerável na velocidade da propagação da informação, da mesma forma que colabora para a criação de ambientes virtuais e de um novo espaço de comunicação, onde podemos citar, por exemplo, o que acontece em uma lan house, onde jovens e adultos se comunicam através de redes sociais e jogos eletrônicos.

Por isso, a empresa de Redmond também está experimentando a inclusão de jogos de vídeo como Minecraft (https://education.minecraft.net/) na educação. A idéia é incentivar alunos a criatividade, a exploração e, acima de tudo, o desenvolvimento de um conteúdo tradicional mais inovador, atraente e mais próximo dos anseios dos estudantes. Os resultados têm sido muito satisfatórios, alcançando grande interesse e motivação dos alunos.

A Microsoft também está fazendo um grande esforço com os Óculos de realidade virtual, a empresa norte-americana introduziu no mercado em 2015, com aplicações educacionais ilimitadas, acreditando que pode tornar-se um dos pilares da educação de amanhã. A Realidade Virtual - VR e Aumentada tem um grande potencial no ambiente educacional, mas ainda é um sonho futurista e com um longo caminho a percorrer.

Segundo Fava (2012), a tecnologia está mudando a educação, não apenas na organização, escolha e disponibilidade dos conteúdos, mas também na distribuição. Isso obriga instituições de ensino a se adaptarem ou irão fracassar nos novos conceitos da sociedade digital.

Portanto, o advento da tecnologia nas escolas não é uma simples mudança na plataforma de distribuição. Deve ser acompanhado por alterações profundas nos métodos de ensino, nas formas de transmissão e na avaliação de conteúdo. 
O Google (https://edu.google.com/intl/pt-BR/?modal_active=none) é outra empresa que mais aposta em tecnologia em ambientes educacionais. Além de oferecer um conjunto completo de serviços para instituições acadêmicas, a empresa de Mountain View lançou várias tendências nos últimos anos, entre os quais:

- Chromebooks - Esses computadores simples, baratos estão se tornando uma das principais tendências em ambientes educacionais. Sua simplicidade de uso e preço baixo fazem com que estes dispositivos se tornem a solução perfeita para trazer a tecnologia para as escolas. (https://www.google.com/intl/pt-BR_br/chromebook/)

- Google Suite - O conjunto de serviços do Google (Drive, Google Docs, Gmail, etc.) é usado também para a educação por pessoas ao redor do mundo todos os dias. O ambiente educacional não é exceção. (https://gsuite.google.com/)

- Plataforma Google Sala de Aula. A plataforma permite gerenciar digitalmente todos os aspectos de uma sala de aula real. Os professores podem acompanhar o trabalho de seus alunos, disponibilizar conteúdo por meio da Internet, atualizar suas habilidades. Todas as tarefas são realizadas diariamente na sala de aula, eles podem ser transferidos para a plataforma de sala de aula. Além disso, a solução está perfeitamente integrada com o resto dos serviços da empresa, sendo assim capaz de interagir com e-mails documentos Drive, Gmail, etc. (https://edu.google.com/intl/pt-BR/products/classroom/)

A Apple (https://www.apple.com/br/education/), por sua vez, também está dirigindo esta transição tecnológica na educação. Além dos clássicos descontos educacionais e algumas colaborações com centros especializados, a empresa da Califórnia tem trabalhado em plataformas de desenvolvimento, como outras soluções de software, como o iTunes U (https://www.apple.com/br/education/ipad/itunes-u/), que pode incorporar todos os seus produtos em ambientes educacionais mais facilmente e de forma invisível, uma ferramenta para instrutores que desejam criar cursos e gerenciar lições e tarefas pela Internet.

Programação, robótica e impressão 3D são três dos ensinamentos mais impulsionados por empresas de tecnologia. E o futuro que nos espera será baseado, em maior ou menor grau, nestes três pilares.

Finalmente, é necessário manter contato direto e permanente entre as instituições de ensino e sociedade civil. O objetivo é o desenvolvimento de novos projetos em conjunto para integrar cada vez mais, a tecnologia e a sala de aula. 


\subsection{Pontos comuns entre as soluções tecnológicas destinadas a educação}

A maioria das propostas mencionadas acima compartilham uma série de características comuns que refletem perfeitamente como a tecnologia está chegando às escolas. Estes são os três aspectos principais:

- Modularidade: Até agora, todos os estudantes seguiam o mesmo ritmo na sala de aula. No entanto, esta metodologia pode gerar diferentes dificuldades para os estudantes com necessidades especiais e / ou habilidades especiais. Em vez disso, com o advento da tecnologia para escolas e mudança metodológica, o ritmo é definido pelo estudante dentro de sua própria limitação, eliminando possíveis frustrações e aumentando o percentual de conteúdos e habilidades desenvolvidas. Assim, alguns alunos podem trabalhar em uma variedade de conteúdo, enquanto outros investem seu tempo em desenvolver outras habilidades.

- Controle Total: Segurança e monitoramento é um dos aspectos-chave na incorporação de tecnologia nas escolas. Portanto, todas as empresas envolvidas oferecem soluções diferentes para monitorar o aluno que faz uso dessas ferramentas.

- Simplicidade: Apesar da formação dada aos professores, a simplicidade de utilização é uma condição essencial para o triunfo da tecnologia como recurso escolar. Software complexos dificultam a penetração de tecnologia nas escolas, provocando a rejeição de novas metodologias e falhando nesta transição progressiva.

O advento da tecnologia à educação não se limita a substituir lápis, caneta, ou papel, ele vai muito além. As metodologias utilizadas, o conteúdo ensinado e como avaliá-los mudam completamente a forma de se educar.

\subsection{Os desafios pela chegada da tecnologia nas escolas}

Todas estas iniciativas e programas desenvolvidos por empresas de tecnologia e instituições oficiais, agem como o ponto central da mudança educacional que nos espera, abrindo um novo mundo de possibilidades, benefícios e, claro, obstáculos a superar.

Para Moraes (1999), vive-se num mundo pequeno e grande ao mesmo tempo, tecido pelas redes de computadores. Não é mais possível controlar o fluxo de informações e o maior 
desafio é produzir conhecimento e realizar um manejo criativo e crítico sobre esse mundo.

A formação de professores é em alguns casos uma das principais dificuldades da transição, pois, vai muito além de distribuir e entregar o conteúdo através de novas ferramentas. As novas tecnologias estão transformando o papel do professor na sala de aula, que deve abandonar seu papel de liderança e fonte de conhecimento para se tornar um mediador que promove autonomia, criatividade e o interesse do estudante pelo assunto. O professor deve deixar de ser o centro das atenções na sala de aula para dividir este lugar com o aluno, colocando-o como centro do método educacional.

Pocho (2003) afirma que o professor precisa mudar a sua postura pedagógica diante desse contexto, principalmente no que diz respeito à construção do conhecimento e democratização do conhecimento, é necessário que ele domine o uso da máquina e a sua utilização pedagógica.

Outra profunda mudança também é reivindicada no conteúdo ensinado em sala de aula. O livro clássico como um problema definido, é obsoleto em todos os níveis. As apresentações de slides, experiências, conteúdos audiovisuais e pesquisas são alguns dos modelos. O conteúdo deve ser mais prático, dinâmico e, acima de tudo, atraente.

A realização de mais aulas práticas ou trabalhos em grupo em sala de aula são alguns exemplos de métodos que os professores devem incentivar nesse novo paradigma educacional, com intuito de preparar os estudantes para enfrentar desafios mais árduos ao longo da sua vida pessoal e profissional.

A memória deve deixar de ser o eixo central do sistema de ensino. Com o advento da tecnologia nas salas de aula, deve ser dado mais valor às habilidades mais úteis como o trabalho em equipe, flexibilidade, síntese ou profunda compreensão do conteúdo. O modelo educacional deve abraçar esta mudança de seus fundamentos.

No entanto, esta mudança metodológica é irrelevante sem um desenvolvimento paralelo de sistemas de avaliação. O sistema clássico (classificação numérica com base em um teste oral, prática ou escrita) é incompatível com este novo paradigma, porque exclui outros parâmetros, tais como a participação dos estudantes, a autonomia na sala de aula, a velocidade com que resolve os desafios colocados pelo professor, o interesse na matéria, sua atitude nos trabalhos em grupo, o progresso ao longo do tempo, ou seja, habilidades valiosas no mercado profissional, que anteriormente não estavam funcionando, mas são vitais para julgar o nível de conhecimento de um estudante.

Para fazer isso, gigantes como Microsoft, Samsung e outras oferecem serviços 
tecnológicos que permitem parâmetros monitorados individualmente, como velocidade de resposta dos alunos, a sua autonomia ou os progressos registados durante o curso do ano letivo em diferentes disciplinas. Desta forma, os professores podem ter uma perspectiva mais real dos estudantes para que possam julgar como eles se comportam.

No entanto, os professores não são os únicos que enfrentam grandes desafios nesta transição educacional, há necessidade de educar e treinar os alunos para fazer o melhor uso dessas novas ferramentas tecnológicas.

O conhecido como "geração digital" não mostra dificuldades no uso de novas tecnologias, mas utilizando-os na produção de conteúdo. Os jovens estão transformando a tecnologia para consumir conteúdo, mas muito poucos fazem para gerá-los. E é aí que os professores e instituições devem trabalhar com seus alunos, mostrando como utilizar as tecnologias para criar conteúdo de qualidade.

Esta é também uma das maiores preocupações refletidas por pais de alunos. A tecnologia é uma faca de dois gumes, especialmente para estudantes em idades mais baixas. Os benefícios da tecnologia na educação são infinitos, mas é necessário ser educado para usar a tecnologia de forma responsável e sustentável.

Além disso, os pais colocam vários desafios nessa transição, o esforço financeiro envolvido para dar aos seus filhos o material tecnológico necessário, faz com que os pais mostrem algum ceticismo sobre essa transição. Eles são a favor da incorporação da tecnologia nas escolas, mas são relutantes à mudança necessária nas metodologias.

No entanto, o maior desafio colocado pelo advento da tecnologia para as escolas está no plano econômico e temporal. Formar professores, adaptando a metodologia de forma satisfatória, gerar novos conteúdos e encaixar todas as peças, exige um elevado esforço financeiro e, acima de tudo, de tempo. Este sacrifício, juntamente com a recusa de muitos professores e instituições em alterar seus métodos, é, sem dúvida, o obstáculo mais difícil de superar.

O esforço financeiro para tornar possível e massificada a utilização das metodologias inovadoras e tecnologias na área da educação, são absolutamente justificadas. A eficácia de treinar os alunos da melhor maneira possível e criar profissionais capacitados, não só para desenvolver a sua profissão, mas também para servir e se adaptar ao futuro volátil que se espera, justifica todos os investimentos. 


\subsection{Os benefícios da tecnologia na educação}

O advento da tecnologia na sala de aula, realizado de forma correta, contribui para maior interesse e melhor desempenho acadêmico dos estudantes. As vantagens proporcionadas são inquestionáveis. A diferença entre estudar uma série de conteúdos utilizando o método tradicional, e fazê-lo usando a tecnologia é o nível de envolvimento do aluno. Ao deixar o sistema atual de memorização e sistemática de conceitos e começar a descobrir, por necessidade natural e interesse próprio, todo esse conhecimento, os resultados começarão a melhorar de maneira incrível e substancial.

Um exemplo simples pode ser encontrado em indivíduos como na Física. Se em vez de mostrar ao aluno os fundamentos teóricos e dezenas de fórmulas que a sustentam, o professor se concentrasse em apresentar o que levou os maiores físicos da história a fazer suas descobertas, os estudantes compreenderiam melhor a base teórica e teria melhores resultados no aprendizado.

Se também, o professor apoiar projetos e experiências que permitem aos alunos observar e testar suas próprias teorias, o resultado é sem dúvida, muito superior ao obtido no presente. Não só é melhor adquirir os fundamentos teóricos, é também necessário que os estudantes pensem por si mesmos, para experimentar e descobrir novas maneiras de alcançar o mesmo objetivo.

No caso de grupos com necessidades e capacidades especiais, os professores são muito otimistas. Soluções tecnológicas propostas pelas principais empresas do setor permitem a aprendizagem mais individualizada e fazem um acompanhamento mais próximo a esses alunos, podendo adaptar o conteúdo para a necessidade do mesmo.

Esta tendência conhecida como "modularidade" ou "aprendizagem personalizada" é uma das peças-chave dessa transformação digital que está se passando na educação. Até agora, todos os estudantes devem seguir o mesmo ritmo de aprendizagem, causando dificuldades para os alunos com necessidades especiais. Graças à modularidade, os alunos podem manter uma taxa de aprendizado individual dentro dos parâmetros desejáveis.

Além disso, a penetração da tecnologia na educação contribui para uma maior versatilidade e globalização. Os estudantes podem acessar informações e interagir com pessoas de qualquer parte do mundo, ficando mais ricas as discussões de conteúdo a ser ensinada em sala de aula. Da mesma forma, a pesquisa pelos próprios alunos é incentivada e pode ir além das competências mínimas ensinadas em sala de aula.

Em paralelo, o uso da tecnologia na educação permite horários mais flexíveis para os 
alunos que necessitam dela. No ensino universitário, materiais audiovisuais têm diferentes plataformas virtuais, permitindo que os alunos as realizem paralelamente às aulas, independentemente dos horários de tais atividades.

Como a tecnologia permite maior flexibilidade do tempo, também permite uma maior flexibilidade geográfica. Graças à internet e a migração gradual de conteúdo educacional privado para plataformas de ensino virtuais públicas, os estudantes podem continuar realizando suas atividades, independentemente de onde estão.

Os alunos com necessidades e capacidades especiais são mais beneficiados pela tecnologia. Barreiras que impediam o caminho desses grupos estão sendo derrubadas, finalmente, promovendo a integração e aumentando as possibilidades no futuro. Várias opções de acessibilidade são oferecidas por dispositivos eletrônicos atuais, permitindo que os alunos com dificuldade de mobilidade ou deficiências auditivas e visuais possam seguir as mesmas metodologias e conteúdo que o resto de seus colegas de classe, eliminando os obstáculos que lhes foram impostos durante décadas.

\subsection{A educação para além da escola}

Além do sistema de ensino tradicional, a tecnologia está tornando possível o surgimento de novas formas de educação. Eles são conhecidos como as tendências de e-learning, que permitem adquirir conhecimentos e avaliá-los através de plataformas virtuais ou aplicativos para smartphones e tablets.

Um dos casos mais populares é o DUOLINGO (https://pt.duolingo.com/), um serviço online que permite que você aprender novas línguas diretamente de um smartphone ou um computador convencional. A implementação bem-sucedida é inquestionável: no Google Play tem mais de 50 milhões de downloads, e seus usuários ativos excedem 10 milhões de usuários por mês.

A fórmula para o sucesso é simples: conteúdo acessível e livre misturado com uma metodologia dinâmica e divertida. E no DUOLINGO, os exercícios práticos são inúmeros, jogos e objetivos pessoais, promovendo assim a continuação da utilização do aplicativo e, portanto, a aquisição de novos conhecimentos.

O avanço da educação para além escolas por meio do progresso tecnológico tem um efeito social e educacional imenso, é mais universal do que nunca e o número aumenta exponencialmente as oportunidades independentemente das nossas condições sociais, 
geográficas ou econômicas.

A um nível mais avançado também são propostos as plataformas de ensino EDX (https://www.edx.org/) e MOOC - massive open online course (http://mooc.org/) que é um termo inglês para maciços abertos online cursos, fundada pelo prestigiado Instituto de Tecnologia de Massachusetts em parceria com a Universidade de Harvard. Na plataforma é possível encontrar cursos on-line sobre administração de empresas, empreendedorismo, eletrônica, programação, mecânica dos fluidos, entre outras. Quase todas as disciplinas têm cursos disponíveis nesta plataforma.

A melhor coisa sobre estes serviços é a possibilidade de adquirir conhecimento de tais instituições de prestígio sem sair do sofá. Um sonho quase impensável há uma década. Além disso, é possível obter um diploma pela instituição que certifica a conclusão do curso e melhoria de nosso conhecimento.

Na Espanha há o MiríadaX (https://miriadax.net/cursos), uma plataforma semelhante a EDX que conta com a colaboração e parceria de algumas grandes instituições como a Telefónica Educação Digital, Universia e do Banco Santander. Tudo com total liberdade e flexibilidade.

No Brasil também temos a Escola Virtual - EV (https://www.ev.org.br/), criada em 2001, a EV é um portal de e-learning dedicado a oferecer cursos gratuitos e 100\% on-line em diferentes áreas, disponibilizando um ambiente virtual completo e que respeita o ritmo e a capacidade de aprendizagem de cada pessoa.

O e-learning está se tornando uma forma de aprender bastante versátil. No entanto, especialistas dizem que o futuro da aprendizagem não será única e exclusivamente dessa forma. O modelo para o qual está migrando mais se aproxima de uma fusão entre a aprendizagem tradicional e o ensino à distância.

O ensino EAD permite ao educando ter uma aprendizagem autônoma, ou seja, o próprio aluno controla o processo ensino- aprendizagem de forma positiva ou negativa, observado seu perfil, pois nessa categoria, segundo Tafner e Silva (2012) os estudantes que buscam cursos à distância devem preencher alguns requisitos, como:

[...] reconhecem suas necessidades de estudo, formulam objetivos para o estudo, selecionam conteúdos, projetam estratégias de estudo, arranjam materiais e meios didáticos, identificam fontes humanas e materiais adicionais e fazem uso delas, bem como quando eles próprios organizam, dirigem, controlam e avaliam o processo de aprendizagem. (Tafner e Silva 2012, p.10)

Dada esta tendência de oferecer conhecimento através da internet, de forma não 
presencial, uma das perguntas mais frequentes é: o que acontecerá no futuro da educação por meio de e-learning? Ao levantar esta questão a vários professores de diversas instituições de ensino, obteve-se a seguinte resposta: o e-learning será posicionado como um pilar essencial do sistema de ensino, mas o modelo para o que migrou mais se aproxima de um modelo híbrido que combina a educação presencial em sala de aula e o ensino a distância.

\section{MATERIAIS E MÉTODOS}

Quanto aos aspectos metodológicos, o estudo foi realizado por meio de referencial teórico. Segundo Lakatos e Marconi (2001), a pesquisa bibliográfica, ou de fontes secundárias, abrange toda bibliografia já tornada pública em relação ao tema de estudo desde publicações avulsas, boletins, jornais, revistas, livros, pesquisas, monografias, teses, material cartográfico, dentre outros.

Portanto, a metodologia a ser utilizada foi a pesquisa bibliográfica, com a leitura de livros, artigos e publicações em geral quanto tema e aos temas a ele relacionado, assim como na verificação das normas pertinentes.

\section{RESULTADOS E DISCUSSÕES}

Diante deste cenário, é que os professores afirmam que a relação pessoal entre professor e aluno, como a educação e a explicação do conteúdo, não poderão ser inteiramente substituídos, especialmente nos níveis mais elementares, como o ensino fundamental e o ensino médio. Porém, estudos e pesquisas realizados por várias entidades refletem uma grande positividade em relação à incorporação de tecnologia nas escolas e, acima de tudo, a mudança metodológica associada a ele.

Segundo Valente (1993) as tecnologias educativas são ferramentas que estão disponíveis e, quando bem utilizadas, produzem transformações significativas no processo de ensino e aprendizagem.

A inclusão da tecnologia lhes permite melhorar a concorrência em competências transversais, conecta o aprendizado de diferentes assuntos, aumentando assim a autonomia dos estudantes na sua própria aprendizagem. 
Da mesma forma, os professores têm observado um aumento do interesse pelas aulas, mais divertidas, dinâmicas e interessantes. Além disso, uma maior colaboração entre os estudantes, um maior esforço para aprender, melhor ambiente de sala de aula e, acima de tudo, a simplicidade contribuem para adquirir melhor o conhecimento estabelecido pelo professor.

Portanto, o advento da tecnologia para as escolas é uma revolução, que deve ser abraçada por professores, alunos e seus pais. Os benefícios são muitos, conforme descrevemos neste estudo e inúmeros são os desafios, mas, apesar de difícil, o novo modelo, é promissor.

\section{CONCLUSÃO}

A tecnologia não é a solução para o problema da aprendizagem. Ensino não pode ser automatizado e o professor não pode ser substituído. No entanto, as novas tecnologias abrem espaços onde os estudantes podem viver experiências difíceis de reproduzir com meios tradicionais, como lápis e papel.

Nestas experiências o estudante pode realizar atividades de exploração no qual é possível manipular os objetos e construir uma visão mais ampla e poderoso conteúdo. Para que isso aconteça à participação do professor é necessária. O professor é aquele que é responsável pela concepção das medidas mais adequadas para explorar o potencial da tecnologia de acordo com as situações e o nível de dificuldades dos alunos na aprendizagem.

A implementação deste projeto de atividades educativas faz parte vital da integração da tecnologia no currículo. Por esta razão, deve-se olhar para o impacto da tecnologia educacional sob duas vertentes: uma que produz sistemas de computador com o qual os alunos podem satisfazer sua necessidade de aprendizado e outra que, produz situações educacionais para que sejam frutíferas do ponto de vista das necessidades do aluno no processo de construção de seu conhecimento.

Na medida em que avança na compreensão destes processos cognitivos, o papel do professor interage com os alunos na presença da tecnologia e do papel que a tecnologia pode desempenhar como agente educacional e, é possível definir de forma mais adequada os problemas que a tecnologia pode trazer e assim desenvolver soluções mais adequadas no futuro da educação. 


\section{REFERÊNCIAS}

BRITO. Glaucia da Silva; PURIFICAÇÃO, Ivonélia da. Educação e Novas Tecnologias: um repensar. São Paulo: Pearson, 2012.

FAVA, Rui. $O$ ensino na sociedade digital. Disponível em: <http://semesp.org.br/portal/index.php>. Acesso em 04/12/2018.

KLOCH, Hermínio; JUNIOR, Vital Pereira dos Santos. Informática básica e tecnologias na educação. Centro Universitário Leonardo da Vinci. Indaial: Grupo UNIASSELVI, 2010.

LAKATOS, E. M.; MARCONI, M. A. Fundamentos metodologia científica. 4.ed. São Paulo: Atlas, 2001.

LEVY, Pierre. Cibercultura. São Paulo: Ed. 34, 1999.

MORAES, Roque. Análise de conteúdo. Revista Educação, Porto Alegre, 1999.

MOSER, Giancarlo. Metodologia do trabalho Acadêmico. Indaial: Editora Grupo Uniasselvi, 2011.

POCHO, C. L. Tecnologia educacional: descubra suas possibilidades na sala de aula.

Petrópolis: Vozes, 2003.

TAFNER, Elisabeth Penzlien da; SILVA, Everaldo da. Metodologia do Trabalho Acadêmico. Indaial: Editora Grupo Uniasselvi, 2a Edição, 2012.

VALENTE, José Armando. Computadores e conhecimentos: repensando a educação. Campinas: UNICAMP, 1993.

Plataforma de Ensino EDX. https://www.edx.org/course/parcerias-publico-privadas-para-oidbx-idb8-1x. Acesso em 06/12/2018.

Plataforma de Ensino MOOC - Massive Open Online Courses. http://mooc.org/. Acesso em 02/12/2018.

Plataforma de Ensino MiríadeX. https://miriadax.net/cursos. Acesso em 24/11/2018.

Plataforma de Ensino DUOLINGO. https://pt.duolingo.com/. Acesso em 24/11/2018.

Plataforma Escola Virtual - Fundação Bradesco. https://www.ev.org.br/. Acesso em 25/11/2018. 
Sitio da Apple - iTunes U. https://www.apple.com/br/education/ipad/itunes-u/. Acesso em 25/11/2018.

Sitio do Google - Sala de Aula. https://edu.google.com/intl/pt-BR/products/classroom/.Acesso em $23 / 11 / 2018$.

Sitio da Microsoft. https://www.microsoft.com/pt-br/education. . Acesso em 26/11/2018.

Sitio da Redmond - Minecraft. https://education.minecraft.net/. Acesso em 04/12/2018. 